\title{
Metode Menentukan Kesahihan Hadis: Teori dan Aplikasi Al-Hakim dalam Kitab Al-Mustadrak 'Ala Shahihain
}

\author{
Eko Zulfikar \\ Institut Agama Islam Negeri (IAIN) Tulungagung \\ Email: ekozulfikar2020@gmail.com
}

\begin{abstract}
Al-Hakim is an influential figure of hadith in the Islamic world. One of his most familiar works is al-Mustadrak 'ala al-Shahihain, which is a manifestation of the application of the method of al-Hakim in determining the validity of the hadith. This paper intends to explore further the method of al-Hakim in determining the validity of the hadith that he manifests in the work. With the descriptive-analytical method, it was concluded that al-Hakim used the principle of ijtihad in determining the method of validity of hadith, and he divides it into four paradigms of viewpoints; (1) seen from the criteria of hadith validity, (2) seen from the hadith classification, (3) seen from the approach of status sanad and matan, and (4) seen from the standard of determining the validity of hadith. As for the steps taken in determining the validity of hadith based on the requirements of the narrators, al-Hakim divides into five categories, namely; (1) hadith that are in accordance with the requirements of Shabihain, (2) hadith that are in accordance with the requirements of al-Bukhari, (3) badith that are in accordance with Muslim requirements, (4) hadith that are in accordance with the requirements of al-Hakim, and (5) badith not judged by alHakim.
\end{abstract}

Keywords: Method, validity of hadith, al-Hakim, al-Mustadrak 'ala al-Shabihain

Abstrak. Al-Hakim adalah tokoh ahli hadis yang berpengaruh dalam dunia Islam. Salah satu karyanya yang familiar adalah al-Mustadrak 'ala al-Shabihain, yang merupakan bentuk manifestasi aplikasi metode al-Hakim dalam menentukan kesahihan hadis. Tulisan ini bermaksud melakukan eksplorasi lebih jauh metode alHakim dalam menentukan kesahihan hadis yang dia manifestasikan dalam karyanya tersebut. Dengan metode deskriptif-analitis, didapati kesimpulan bahwa al-Hakim menggunakan prinsip ijtihad dalam menentukan metode kesahihan hadis, dan ia membaginya menjadi empat paradigma sudut pandang; (1) dilihat dari kriteria kesahihan hadis, (2) dilihat dari klasifikasi hadis, (3) dilihat dari pendekatan status sanad dan matan, dan (4) dilihat dari standar penentuan kesahihan hadis. Adapun langkah yang dilakukan dalam menentukan kesahihan hadis berdasarkan syarat perawi, al-Hakim membagi menjadi lima kategori, yakni; (1) hadis yang sesuai dengan syarat Shabihain, (2) hadis yang sesuai dengan syarat al-Bukhari, (3) hadis 
yang sesuai dengan syarat Muslim, (4) hadis yang sesuai dengan syarat al-Hakim, dan (5) hadis yang tidak dinilai al-Hakim.

Kata kunci: Metode, kesahihan hadis, al-Hakim, al-Mustadrak 'ala al-Shahihain

\section{PENDAHULUAN}

Dalam kajian hadis, studi sanad menjadi salah satu objek penelitian yang sentral untuk menentukan otentisitas dan hierarki sebuah hadis. Sebab, di samping dalam penerimaan hadis mengharuskan keotentikan dan validitas hadis berasal dari Nabi Saw, juga sanad hadis akan sangat menentukan derajat setiap hadis itu sendiri, apakah tergolong sabih, hasan atau dha'if, tergantung tingkat kualifikasi perawi hadisnya -memenuhi kriteria 'adalah, dhabith, dan tsiqah. Kemudian kajian selanjutnya melakukan kritik hadis dengan studi aljarh wa al-ta'dil, dan melakukan verifikasi hadis dengan al-tashih wa al-tadh'if terhadap semua hadis dan sanadnya. Namun ulama Muhaddisin berbeda pendapat dalam memberikan kriteria atau syarat bagi perawi hadis untuk dievaluasi, apakah hadis-hadis yang diriwayatkannya dapat diterima (maqbul) atau ditolak (mardud).

Salah satu ahli hadis yang ikut andil dalam menentukan kesahihan hadis adalah al-Hakim. Ia termasuk ulama yang gampang dan sangat longgar dalam memverifikasi hadis (al-tashih wa al-tadh'if) (Amarudin dan Syafril Mufid, 2013, tanpa halaman). Meski demikian, al-Hakim mampu menyusun acuan dasar dengan tertib dalam menentukan kesahihan hadis. Metode yang meliputi prinsip-prinsip dan pendekatan status sanad dan matan cukup jelas, sehingga ia tidak hanya mempunyai paradigma berpikir sistematis, namun juga buah hasil ijtihadnya menjadi sumber rujukan ulama setelahnya. Al-Hakim juga mendapatkan predikat dan apresiasi cukup baik dari hasil buah karyanya dibandingkan dengan karya lain, khususnya pada karya monumentalnya kitab al-Mustadrak 'ala al Shabihain.

Kitab al-Mustadrak merupakan bentuk manifestasi aplikasi metode alHakim dalam menentukan kesahihan hadis. Kitab ini memiliki superioritas 
tinggi yang tampak pada penggunaan pendekatan standar ganda dalam ijtihadnya. Dengan bahasa lain, kitab ini memiliki tujuan agar lebih akomodatif dan partisipatif dalam menghadapi hadis yang pada masanya mengalami degradasi ijtihad dan stagnasi penghargaan terhadap kedudukan hadis. Namun kitab ini juga tidak terbebas dari kritikan yang berimplikasi pada evaluasi positif dan negatif para ulama terhadap al-Hakim.

Dalam kitab al-Mustadrak ini, al-Hakim juga menyadari terdapat banyak kekurangan dalam karya yang disusunnya. Banyaknya hadis yang dinilai dha'if dan tidak layak disandarkan kepada Nabi merupakan bukti konkret kekurangan al-Hakim. Terlepas dari hal tersebut, buah hasil ijtihadnya dalam kitab al-Mustadrak berhasil membawa pengaruh dan kontribusi besar bagi ulama setelahnya hingga kini. Paradigma berpikirnya sangat fleksibel, luwes dan kontekstual dengan situasi pada masanya, dan secara konseptual mengaplikasikan aspek ontologi, epistemologi, dan aksiologi dalam menentukan kesahihan hadis.

Dengan mengacu pada karakteristik pemikiran al-Hakim yang memberi pengaruh sepanjang masa ini-lah, penulis terdorong untuk mengeksplorasi sedikit lebih jauh metode al-Hakim dalam menentukan kesahihan hadis dan aplikasinya dalam kitab al-Mustadrak 'ala al-Shabihain. Penelitian tentang alHakim ini sebenarnya masih relatif sedikit dilakukan. Apalagi tentang penelitian yang secara spesifik mengulas tentang metode menentukan kesahihan hadis dan aplikasinya dalam kitab al-Mustadrak. Sebagi contoh, tulisan Agusri Fauzan membahas tentang Studi Komparatif Teori Ilmu Hadis AlHakim Al-Naisabury Dan Ibnu Shalah. Dalam pembahasannya, ia hanya mengupas tentang seputar definisi dan syarat-syarat hadis shabih dan dha'if menurut Al-Hakim dan Ibnu Shalah (Agusri, 2018, h. 51-68).

Begitu juga dalam tulisan Amarudin dan Syafril Mufid tentang Metode Keshabihan Hadis Al-Hakim (Telaah Atas Kitab al-Mustadrak 'ala al Shabihain). Dalam tulisan ini, mereka hanya mengupas dan fokus pada metode 
penetapan keshahihan hadis yang terbagi menjadi empat, yakni berdasarkan ijtihad, prinsip status sanad, prinsip status matan, dan kriteria kritik sanad, tanpa menyinggung aplikasi dan implementasi status hadis berdasarkan penilaian al-Hakim dalam kitab al-Mustadrak 'ala al-Shabibain beserta contohcontohnya (Amarudin dan Syafril Mufid, 2013, tanpa halaman).

Oleh karena itu, tulisan ini berbeda dengan tulisan yang ada sebelumnya, karena orientasi pembahasannya mengulas tentang metode aplikasi keshahihan hadis al-Hakim dan contoh-contohnya dalam kitab alMustadrak. Dengan demikian, analisa kritis penulis akan lebih ditekankan pada deskripsi dengan metode kualitatif, spesifik pada studi pustaka (library research) murni dengan menitik-beratkan al-Mustadrak 'ala al-Shabihain sebagai data primer, serta menggunakan pendekatan filosofis dan ilmu hadis.

\section{HASIL DAN PEMBAHASAN}

\section{Sketsa Biografis Al-Hakim}

Nama lengkap al-Hakim adalah al-Hafidz Muhammad bin 'Abdullah bin Muhammad bin Hamdun bin Nua'im al-Hakim Abu 'Abdullah al-Dhabbi al-Thahmani al-Naisaburi al-Syafi'i, familiar dengan sebutan Ibn al-Bayyi' (alHakim, 1978, h. 7). Ia dilahirkan di Naisabur pada hari Senin, 12 Rabi’ul Awal $321 \mathrm{H}$, dan wafat tahun $405 \mathrm{H}$ (al-Falah, t.th, h. 17). Ayah al-Hakim bernama 'Abdullah bin Muhammad bin Hamdun, merupakan seorang pejuang yang dermawan dan sangat loyal terhadap penguasa Bani Saman yang menguasai daerah Samaniyyah (Ibn Katsir, 1977, h. 220). Pada abad ketiga, daerah Samaniyyah ini telah banyak melahirkan ahli hadis ternama, di antaranya alBukhari, Muslim, Abu Dawud, al-Tirmidzi, al-Nasai, dan Ibn Majah. Secara tidak langsung, kondisi sosio-kultural ini-lah yang mempengaruhi al-Hakim sebagai seorang pakar hadis pada abad keempat Hijriah (Najwah, 2003, h. 240).

Asal mula al-Hakim bergelut dalam bidang hadis dilatarbelakangi sang ayah yang hidup di tengah-tengah masyarakat pecinta ilmu pengetahuan. Hal 
ini mendorong sang ayah lebih mencintai ilmu agama khususnya hadis yang telah gencar menjadi kajian utama pada masa itu. Karena kecintaannya terhadap hadis, sang ayah sempat bertemu dengan al-Bukhari dan Muslim, bahkan sempat pula menerima hadis dari Ibn Khuzaimah (Abdurrahman, 2000, h. 29). Dengan lingkungan sedemikian rupa, akhirnya sang ayah mendorong al-Hakim untuk lebih menekuni hadis. Peran sang ayah ketika berguru pada Ibn Khuzaimah juga semakin mendorong al-Hakim untuk menggeluti hadis, bahkan al-Hakim menjadikan sang ayah suri-teladan dalam mengasah paradigma berpikirnya.

Pada masa kecil, al-Hakim belajar agama pertama kali dari sang ayah dan anggota keluarga lainnya. Setelah itu pada usia 13 tahun $(334 \mathrm{H})$, ia mulai belajar hadis secara khusus dan berguru kepada Abu Hatim Ibn Hibban. Tidak cukup sampai disitu, al-Hakim kemudian melakukan perlawatan ilmiah ke berbagai daerah untuk dapat berlajar langsung kepada para ahli hadis, agar mata rantai sanad yang diterimanya memiliki nilai yang tinggi, karena menurut al-Hakim, sebagaimana yang disyaratkan oleh al-Bukhari, suatu sanad hadis bernilai tinggi apabila terdapat liqa' (pertemuan) antara guru dan murid, meski hanya sekali dan sebentar (Najwah, h. 241).

Di antara daerah-daerah yang didatangi oleh al-Hakim adalah Irak, Khurasan, dan Hijaz. Kota-kota tersebut pada masa itu banyak bermukim ulama dalam berbagai disiplin keilmuan, terutama ahli hadis. Merasa belum cukup dengan perlwatan intelektualnya ke daerah-daerah tersebut, al-Hakim kembali melakukan perjalanan untuk kedua kalinya pada tahun $368 \mathrm{H}$, bertepatan pada usia 47 tahun. Perjalanan ilmiah seperti ini merupakan tradisi di kalangan ahli hadis, karena adanya asumsi bahwa ahli hadis yang hanya mengandalkan riwayat dari ulama kampung halamannya tidak memiliki bobot ilmiah yang tinggi. Di samping itu, perjalanan ini diperlukan untuk mendiskusikan temuan dan pandangan pendapatnya tentang hadis dan ilmu hadis. Sebagaimana kitab al-Mustadrak telah didiskusikan al-Hakim dengan 
salah seorang gurunya, yaitu al-Daruquthni yang bermukim di Irak (Abdurrahman, h. 31-32).

Kemasyhuran al-Hakim di kalangan ahli hadis tidak bisa dilepaskan dari keterlibatan guru-gurunya yang banyak memberikan kontribusi keilmuan atas perkembangan intelektualitasnya. Dalam lintasan sejarah diungkapkan bahwa al-Hakim telah berguru kepada kurang lebih 1000 orang. Di antara gurugurunya yang berada di berbagai daerah yakni Muhammad bin 'Ali alMudzakir, Muhammad bin Ya'qub al-A'sham, Muhammad bin Ya'qub alSyaibani, Muhammad bin Ahmad al-Balawaih al-Jallab, Abu Ja'far Muhammad bin Ahmad bin Sa'id al-Razi, Muhammad bin 'Abdillah Ahmad al-Safar, 'Ali bin al-Fadhl al-Suturi, 'Ali bin 'Abdillah al-Hakam, Isma'il bin Muhammad al-Razi, Muhammad bin al-Qaim al-Ataki, Abu Ja'far Muhammad bin 'Abdullah al-Baghdadi al-Jamal, Muhammad bin Muammal al-Majarisi, Muhammad bin Ahmad bin Mahlub, Abu Hamid Ahmad bin 'Ali bin Husnawaih, al-Hasan bin Ya'qub al-Bukhari, dan al-Qasim bin Abu alQasim al-Yasari (Abdurrahman, h. 242).

Selain itu, guru-gurunya yang lain adalah Abu al-Bar Ahmad bin Ishaq al-Sabagi, Ahmad bin Muhammad bin 'Abd al-Anzi, Muhammad bin Ahmad al-Syaibi, Abu 'Ali al-Husain bin 'Ali al-Naisaburi al-Hafidz, Hazib bin Ahmad al-Thusi, 'Ali bin Hamsad al-'Adl, Muhammad bin Shalih bin Hani', Abu Nad Muhammad bin Muhammad al-Faqih Abu 'Umar, 'Usman alDaqaq al-Baghdadi, Abu Bakar al-Najjad, 'Abdullah bin Darustawaih, Abu Sahl bin Ziyad, 'Abd al-Baqi' bin Qani', 'Abdurrahman bin Hamdan al-Jallab, al-Husain bin Hasan al-Thusi, 'Ali bin Muhammad bin 'Uqbah al-Syaibani, Muhammad bin Hatim bin Khuzaimah al-Kashi, Abu Qadir al-Ziyadi, alQadhi Abu Bakr al-Hirri, dan masih banyak lagi yang lainnya (Zainal Arifin, 2010, h. 178-179).

Dari sekian banyak guru al-Hakim tersebut, al-Daruquthni, Ibn Hibban dan Abu 'Ali al-Naisaburi adalah guru yang memiliki kedudukan khusus di 
mata al-Hakim. Selain alasan karena intensitas pertemuannya dengan alHakim yang cukup lama, juga karena kapasitas keilmuan mereka sangat memadai untuk diimitasi oleh al-Hakim yang berujung memiliki banyak murid periwayat hadis.

Dalam perjalanan hidupnya yang berlangsung kurang lebih selama 84 tahun, al-Hakim telah memberikan banyak kontribusi dalam bidang hadis melalui karya monumentalnya al-Mustadrak 'ala Shabihain. Di samping itu ia juga masih memiliki banyak karya, antara lain: al-Arba'in, al-Asma wa al-Kunya, al-Iklil fi Dalail al-Nubuwwah, Amali al-'Asyiyyat, al-Amali, Tarikh Naisabur, alDu'a, Sualat al-Hakim li al-Daruquthni fi al-Jarb wa al-Ta'dil, Sualat Mas'ud alSajzi li al-Hakim, al-Du'afa', Ilal al-Hadits, Fadhail Fatimah, Fawaid al-Syuyukh, Ma Tafarrada bibi Kullun min al-Imamain, al-Madkhal ila 'Ilmi al-Shahih, alMadkhal ila Ma'rifati al-Mustadrak, Muqakki al-Akbbar, Mu'jam al-Syuynkh, Ma'rifah 'Ulum al-Hadits, al-Ma'rifah fi Drikeri al-Mukhadhramin, Maqtal alHusain, dan Manaqib al-Syafii (al-Hakim, h. 11-12).

\section{Metode Al-Hakim dalam Menentukan Kesahihan Hadis}

Dalam menentukan kesahihan hadis, al-Hakim menggunakan metode murni penalaran ijtihad. Prinsip dasar dengan metode ini bukan sesuatu yang baru, karena ulama sebelumnya seperti al-Ramahurmuzi dan beberapa ulama hadis lain pernah menggunakan konsep ini. Secara tegas, al-Hakim membagi konsep ijtihadnya ke dalam empat sudut pandang, yakni: (1) dilihat dari kriteria kesahihan hadis; (2) dilihat dari klasifikasi hadis; (3) dilihat dari pendekatan status sanad dan matan; dan (4) dilihat dari standar penentuan kesahihan hadis.

\section{Dilihat dari kriteria kesahihan hadis}

Dalam menentukan kriteria kesahihan hadis, al-Hakim membaginya ke dalam empat paradigma pembahasan. Pertama, ulasan tentang perawi yang tsiqah. Tsiqah dapat diartikan sebagai kemampuan hafalan yang sempurna atau sebagai kompilasi antara 'adalah al-rawi dan dhabit-nya (Isma'il, 1988, h. 106). 
Sementara al-Hakim hanya mengemukakan tiga sifat yang mengindikasikan seseorang dapat disebut 'adl; beragama Islam, tidak berbuat bid'ah, dan tidak berbuat maksiat. Kriteria ini paling sedikit dibandingkan dengan ulama lainnya (Abdurrahman, h. 94). Dengan demikian al-Hakim termasuk orang yang menolak rawi yang tidak 'adl dan dhabit.

Kedua, ungkapan bimitsliba. Bagian ini ada kaitannya dengan rijal al-badits yang digunakan Syaikhani (al-Bukhari dan Muslim) (al-Jaza'iri, 416 H, h. 23). Dalam al-Mustadrak, al-Hakim sering menyebut orang-orang khusus pada sanad yang digunakannya sebagai rijal al-syaikhani - bukan rijal al-hadits, sehingga memberikan perspektif berbeda bagi ulama sesudahnya.

Ketiga, tentang kriteria fuqaha. Dalam ijtihad al-Hakim, ia menentukan kriteria kesahihan hadis jika sudah diriwayatkan oleh orang yang tsigah dan sudah memenuhi kriteria al-Bukhari dan Muslim, atau salah seorang daripadanya termasuk memenuhi kriteria fuqaba Islam. Namun perlu dicermati secara seksama apakah al-Hakim menggunakan standar ganda dalam hal ini, karena menurut sebagian ulama ada perbedaan antara ahli fiqih dan ahli hadis dalam menentukan status hadis (ahli hadis cenderung lebih ketat dalam menentukan status hadis sementara ahli fiqih lebih longgar).

Keempat, pembahasan ziyadah al-tsiqah. Hadis yang diterima para rawi acapkali melalui jalan periwayatan atau sanad, namun bila terdapat seorang rawi sendirian dengan disertai suatu "ungkapan atau perkataan" tambahan yang tidak terdapat pada hadis yang diriwayatkan rawi yang lain, padahal masih diadopsi dari guru yang sama, maka hadis tersebut dinamakan riyadah al-tsiqah (Abdurrahman, h. 100-101). Al-Hakim termasuk kalangan ahli hadis yang menerima konsep ini, sementara ahli hadis lain menolaknya.

\section{Dilihat dari klasifikasi hadis}

\footnotetext{
${ }^{1}$ Ada yang menafsirkan sebagai rawi yang mengacu pada rawi yang menjadi persyaratan Syaikhain, ada pula yang mendefinisikan 'ala syarth al-shahihain bukan hanya pada diri rijal, tetapi juga sifat-sifat persis dengan rijal yang digunakan Syaikhain secara mandiri seperti kemasyhuran, keteguhan, keadilan rawi dan lain-lain.
} 
Al-Hakim mengklasifikasian hadis sekurangnya menjadi dua bagian, yaitu shahih dan dha'if (tidak termasuk hadis hasan). Menurut al-Hakim, hadis shahib memiliki dua level, ada konsensus tentang kesahihannya dan ada pula yang tidak. Di antara hadis yang tidak disepakati kesahihannya adalah hadis hasan yang termasuk dalam kategori hadis shahih. Bagi al-Hakim, konsep hadis shabih dan hasan tidak sama dan tidak sebanding dengan konsep shabih dan dha'if menurut ulama lainnya. Dengan kata lain, shabih dan dha'if menurut alHakim berbeda dengan ulama lain meskipun istilah teknis yang dipakai sama. Hadis yang dianggap hasan oleh ulama lain dimasukkan al-Hakim ke dalam kategori hadis shabih atau dalam ungkapan al-Hakim disebut shabih al-Isnad, sementara hadis dha'if yang palsu atau maudbu' dalam tingkatan hadis, menurut al-Hakim ada yang boleh dipergunakan (Abdurrahman, h. 259-260).

\section{Dilihat dari pendekatan status sanad dan matan}

Dalam membahas kriteria pendekatan status sanad, al-Hakim mengulasnya dengan mengungkap istilah ashah al-asanid yang dibagi menjadi empat; (1) suatu hadis dapat diterima dari abl al-bait jika jalurnya berasal dari sanad Ja'far bin Muhammad, dari ayahnya, dari kakeknya, dari Ali bin Abi Thalib, (2) jika suatu hadis diterima dari jalur Abu Bakr, maka sanad yang paling shabih adalah melalui Isma'il bin Abi Khalid, dari Qais bin Abi Hazim, dari Abu Bakar, (3) kesahihan sanad dari jalur Abu Hurairah ialah al-Zuhri, dari Sa'id bin Musayyab, dari Abu Hurairah, dan (4) sanad yang paling shahib untuk hadis yang diterima Anas adalah Malik bin Anas, dari al-Zuhri, dari Anas.

Istilah lain yang digunakan al-Hakim untuk menentukan status hadis shahih adalah asbah al-asanid. Menurut al-Hakim, termasuk sanad dalam kategori ini ada tiga; (1) sanad hadis yang paling kuat melalui jalur orangorang Mesir ialah hadis yang diterima dari al-Lais bin Sa'd, dari Yazid bin Abi Hubaib, dari Abi al-Khair, dari Uqbah bin Amir al-Juhani, (2) sanad hadis paling teguh melalui jalur orang-orang Syam ialah hadis yang diterima dari 
'Abd al-Rahman bin Amr al-Awza'i, dari Hasan bin Athiyah dari sahabat, dan (3) sanad yang paling kuat melalui jalur orang-orang Khurasan ialah hadis yang diterima dari al-Husain bin Waqid, dari 'Abdullah bin Buraidah dari ayahnya.

Dalam menentukan sanad yang paling lemah, al-Hakim menggunakan istilah auba' al-asanid. Bagi al-Hakim, ada tiga transmisi hadis yang menurutnya paling lemah; (1) sanad hadis paling lemah dari abl al-bait ialah hadis yang diterima melalui jalur Amr bin Syimr, dari Jabir al-Ju'fi, dari alHarits al-A'war, dari Ali, (2) sanad hadis yang paling lemah dari Abu Bakar adalah hadis yang diterima melalui jalur Shadaqah bin Musa al-Daqiqi, dari Farqad al-Sabkhi, dari Murrah al-Thayyib, dari Abu Bakar, dan (3) paling lemahnya sanad hadis dari 'Aisyah ialah suatu hadis yang diterima dari kalangan orang-orang Bashrah melalui al-Harits bin Syibi, dari Ummi Nu'man al-Kindiyah, dari 'Aisyah yang berbentuk naskah (Abdurrahman, $h$. 109-111).

Kemudian dalam mengungkapkan kaidah sanad hadis tentang jauh dan dekatnya suatu sanad, al-Hakim memakai ungkapan sanad 'ali dan nazil. Hadis 'ali bersanad pendek atau dekat, sementara hadis nazil bersanad panjang atau jauh. Telaah 'ali dan nazil tidak pernah dilewatkan oleh ahli hadis mana pun. Ulama pasca al-Hakim, seperti al-Baghdadi, Ibn Syalab, al-Iraqi, dan alAsqalani mengupasnya dengan panjang-lebar (Abdurrahman, h. 121). Menurut al-Hakim, riwayat 'ali lebih tinggi tarafnya karena terdapat ulama masyhur dan familiar di dalamnya. Namun sanad 'ali ini tidak selamanya paling shahih, sebab sanad nazil juga bisa berkedudukan paling shabih jika dalam nazil terdapat ulama masyhur dan familiar.

Sementara berkaitan dengan status matan, al-Hakim meyakini bahwa hadis sahih tidak hanya berkutat pada sanad semata tetapi juga pada matan. Hal ini disebabkan karena manusia pada umumnya tidak bisa lepas dari kesalahan. Untuk itu al-Hakim menyatakan: "Sesungguhnya hadis shabih itu 
tidak hanya diketahui dengan kesahihan riwayat, tetapi juga dengan pemahaman, hafalan, dan banyak mendengar" (Abdurrahman, 2000, h. 114).

\section{Dilihat dari standar penentuan kesahihan hadis}

Standar penentuan kesahihan hadis yang digunakan al-Hakim adalah menerapkan double standart, yakni tasyaddud (ketat) terhadap hadis-hadis yang terkait dengan 'aqidab dan syari'ah (hukum halal, haram, muamalah, dan nikah) dan tasabul (longgar) terhadap hadis-hadis yang terkait fadhail al-a'mal, sejarah Rasul dan para sahabat.

\section{Aplikasi Metode Al-Hakim Dalam al-Mustadrak 'ala al-Shahihain}

\section{Latar-belakang penyusunan kitab al-Mustadrak}

Dalam menyusun kitab al-Mustadrak, al-Hakim dilatarbelakangi oleh gugahan hatinya untuk menelisik hadis sahih yang setingkat dengan Shahihain (kitab al-Bukhari dan Muslim). Menurut al-Hakim, hadis yang memenuhi kriteria kesahihan masih berserakan di luar Shabihain, baik yang belum dicatat ulama hadis maupun yang sudah dikodifikasi dalam beberapa kitab hadis. Tidak aneh jika banyak sanad dan atau matan hadis yang diriwayatkannya sama dengan yang diriwayatkan oleh ulama lainnya. Di samping itu, ada pula matan hadis yang sama melalui sanad yang berbeda atau ada hadis semakna dengan diriwayatkan ulama lain tetapi dengan menggunakan matan yang berlainan. Asumsi al-Hakim ini semakin kuat atas dasar ucapan al-Bukhari, bahwa masih banyak hadis sahih yang tercecer yang belum sempat dihimpunnya (al-Jurjani, 1988, h. 131).

Alasan al-Bukhari tidak mengumpulkan banyak hadis dalam kitab alJami' al-Shahih-nya antara lain karena takut berkepanjangan. Selain itu, tersusunnya karya tersebut merupakan respons terhadap anjuran gurunya, Ishaq bin Rahawaih. Sementara Muslim bin al-Hajjaj, dalam menghimpun hadis dalam kitabnya, ia tidak merangkum seluruh hadis sahih yang diketahuinya. Hanya saja hadis yang dihimpunnya itu sudah memenuhi standar kesahihan hadis yang telah disepakati oleh para ahli hadis yang 
menjadi guru-gurunya, seperti Ahmad bin Hanbal, Yahya bin Ma’in, dan Usman bin Abi Syaibah (Abdurrahman, h. 12-13).

Pernyataan al-Bukhari dan Muslim itu-lah yang dijadikan patokan dasar al-Hakim, bahwa langkah yang ditempuhnya merupakan suatu keharusan dan tidak menyalahi tradisi ulama yang menjadi pendahulunya. Al-Hakim meyakini kebenaran yang dimilikinya karena hadis yang dikatakan sahih oleh kedua imam tersebut masih banyak di luar karyanya. Ia juga yakin tidak menyalahi tradisi karena dalam menentukan status hadis yang ditulisnya, ia melalui metode ilmiah yang dapat dipertanggung-jawabkan, yakni proses penentuan validitas kesahihan hadis melalui seleksi sanad dan matan (alHakim, h. 3).

\section{Sistematika dan kandungan kitab al-Mustadrak}

Kitab al-Mustadrak ini adalah termasuk kitab induk hadis yang berintikan pada penjelasan matan hadis. Ia merupakan salah satu kitab yang paling familiar dalam jenisnya (Arif Wahyudi, 2013, h. 7). Sistematika penyusunan kitab yang ditulis al-Hakim ini adalah berdasarkan bab-bab fiqih sebagaimana yang dilakukan al-Bukhari dan Muslim dalam kitabnya. Kitab alMustadrak termasuk salah satu kitab yang mengumpulkan hadis-hadis shahih yang tidak termuat dalam kitab-kitab shabih abad ketiga. Di antara kitab-kitab pada abad keempat ini yang tertinggi derajatnya adalah shabih Ibn Khuraimah, shabih Ibn Hibban, dan shabih al-Hakim (al-Shiddiqy, 1988, h. 116).

Dalam kandungan kitabnya, al-Hakim menyebutkan tiga macam hadis; pertama, hadis-hadis shahib menurut syarat al-Bukhari dan Muslim atau salah satunya, namun mereka berdua tidak meriwayatkan dalam kitab shabih-nya. Kedua, hadis-hadis shahih menurut al-Hakim, meski tidak sesuai dengan syarat al-Bukhari dan Muslim atau salah satunya yang ia istilahkan dengan shabihah al-isnad. Ketiga, hadis-hadis yang tidak shabih menurut al-Hakim, tetapi ia jelaskan sebabnya. 
Secara umum, kitab al-Mustadrak ini termasuk al-Jami' yakni kitab hadis yang memuat berbagai studi Islam yang meliputi bidang akidah, syariah, dan akhlak. Selain itu, di dalamnya terdapat berbagai hal yang berkaitan dengan tarikh, tafsir, sirah Nabawi, sahabat, maghari, peristiwa masa lalu, dan lain-lain. Jumlah hadis dalam al-Mustadrak diperkirakan sebayak 8690 hadis yang terkumpul dalam empat jilid besar (al-Thahan, 1995, h. 72).

\section{Status hadis dalam kitab al-Mustadrak}

Status hadis yang dinyatakan sahih oleh al-Dzahabi dalam al-Mustadrak berjumlah 1930 hadis. Namun bagi al-Hakim, hadis-hadis yang terdapat di dalam kitabnya memiliki banyak ragam; ada yang secara eksplisit disebutkan memenuhi syarat Syaikhani, ada yang hanya memenuhi syarat al-Bukhari atau Muslim semata, ada yang hanya dikatakan shahih al-isnad (sahih sanadnya); dan ada pula yang tidak dinilai sama sekali. Meskipun al-Hakim sudah menentukan evaluasinya sendiri, namun ulama lain ada yang tidak sepakat sehingga ia sering dikritik sebagai sosok ulama yang tidak konsisten dalam mengimplementasikan kriteria yang ia sodorkan.

Dalam al-Mustadrak, hadis yang memenuhi kriteria shabihain menurut telaah al-Dzahabi sebanyak 985 hadis, kriteria al-Bukhari sebanyak 113 hadis, dan kriteria Muslim Sebanyak 571 hadis. Sedangkan yang menggunakan shabih al-isnad berjumlah 3447 hadis; dan sisanya termasuk hadis yang tidak dinilai oleh al-Hakim (Abdurrahman, h. 216). Ini berarti hadis yang tidak dinilai al-Hakim berkisar sebanyak 3575 hadis. Adapun beberapa istilah yang digunakan al-Hakim dalam kitab al-Mustadrak, antara lain seperti ungkapan:

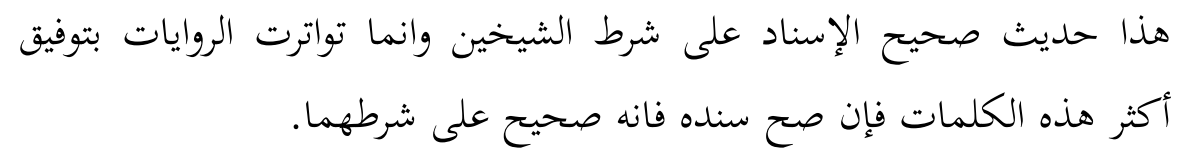

"Hadis ini sahih sanadnya berdasarkan kriteria syaikhain. Sementara riwayat mutawatir (yang banyak riwayatnya) adalah riwayat yang maknanya paling banyak kecocokkannya dengan kalimat-kalimat ini. Apabila hadis ini sahih sanadnya, maka hadis itu sahih berdasarkan 
kriteria yang digunakan kedua imam tersebut (al-Bukhari dan Muslim)" (al-Hakim, h. 127).

Ungkapan ini mengindikasikan relasi dengan pemaparan sebelumnya, bahwa al-Hakim memakai ungkapan bimitsliha sebagai kata kunci ijtihad dalam menentukan kesahihan hadis. Ia juga sering menyebut orang-orang khusus pada sanad yang digunakannya sebagai rijal al-syaikhain. Setidaknya ada lima kategori hadis yang ditetapkan al-Hakim sebagai indikator status hadis dalam al-Mustadrak, yaitu:

Pertama, hadis yang sesuai dengan syarat Shabihain. Ketika al-Hakim هذا حديث mentukan hadis yang memenuhi syarat shabihain, ia mengatakan; (Hadis ini memenuhi persyaratan al-Bukhari dan Muslim, tetapi mereka tidak meriwayatkannya). Hadis yang memenuhi persyaratan shabihain kurang lebih sebanyak 985 hadis, dan ini acapkali diberi inisial oleh al-Dzahabi dalam talkhish-nya dengan menggunakan huruf "kha" untuk al-Bukhari dan "mim" untuk Muslim. Inisial seperti ini memperlihatkan bahwa terdapat rijal khusus yang digunakan oleh kedua imam tersebut secara keseluruhan dalam sanadnya, baik secara kolektif antara syaikhain maupun secara personal-individual. Sebagai contoh, al-Hakim menulis hadis tentang kewajiban memberi fidyah kepada fakir miskin bagi orang tua yang tidak mampu berpuasa. Pada kesempatan ini, al-Hakim menyebutnya dengan "ala Syartbibima" yang berarti sesuai dengan syarat syaikhain.

Dalam menggunakan persyaratan di atas, al-Hakim tidak memiliki konsistensi untuk penetapan, karena ada juga hadis yang sebenarnya hanya memenuhi persyaratan di antara keduanya; al-Bukhari atau Muslim. Sebagaimana contoh ketika al-Hakim meriwayatkan hadis tentang hubungan antar umat manusia; 


$$
\begin{aligned}
& \text { حدثنا أبو العباس محمد بن يعقوب حدثنا إبراهيم بن مرزوق حدثنا أبو داود } \\
& \text { حدثنا شعبة عن أبي بلج. وأخبرني أحمد بن يعقوب الثقفي حدثنا عمرو بن } \\
& \text { حفص السدوسي حدثنا عاصم بن علي حدثنا شعبة عن يحيى بن أبي سليم و } \\
& \text { هو أبو بلج · و هذا لفظ حديث أبي داودـ قال: سمعت عمرو بن ميمون يحدث } \\
& \text { عن أبي هريرة عن النبي صلى الله عليه و سلم قال: من سره أن يجد حلاوة } \\
& \text { الإيمان فليحب المرء لا يحبه إلا الله. }
\end{aligned}
$$

"Telah menceritakan kepada kami Abu al-Abbas Muhammad bin Ya'qub, telah menceritakan kepada kami Ibrahim bin Marzuq, telah menceritakan kepada kami Abu Dawud, telah menceritakan kepada kami Syu'bah dari Abi Balaj. Telah mengabarkan kepadaku Ahmad bin Ya'qub al-Tsaqafi, telah menceritakan kepada kami 'Amr bin Hafsh alSadusi, telah menceritakan kepada kami 'Ashim bin 'Ali, telah menceritakan kepada kami Syu'bah dari Yahya bin Abi Salim, yakni Abi Balaj. Redaksi ini hadis dari Abu Dawud, ia berkata; aku mendengar 'Amr bin Maimun bercerita dari dari Abu Hurairah, dari Nabi Saw, beliau bersabda: "Barangsiapa yang tertarik untuk mendapatkan lezatnya iman maka cintailah seseorang, ia tidak mencintainya kecuali karena Allah Swt."

$$
\begin{aligned}
& \text { هذا حديث لم يخرج في الصحيحين و قد احتجا جميعا بعمرو بن ميمون عن } \\
& \text { أبي هريرة و احتج مسلم بأبي بلج و هو حديث صحيح لا يحفظ له علة. } \\
& \text { تعليق الذهبي قي التلخيص: لا يحتج به يعني بأبي بلج. }
\end{aligned}
$$

"Hadis ini tidak diriwayatkan dalam kitab Shahibain. Namun mereka menjadikan hujjah dengan riwayat Amr bin Maimun dari Abu Hurairah, dan Muslim berhujjan dengan riwayat Abi Balaj. Ini termasuk hadis sahih yang terdapat kecacatan" (al-Hakim, h. 440).

Pada hadis tersebut, terdapat rawi yang bernama Yahya bin Abi Salim yang disebut sebagai Abi Balaj. Menurut al-Hakim, al-Bukhari dan Muslim mengambil hujjah yang disandarkan kepada Abi Balaj, namun pernyataan alHakim ditampik al-Dzahabi bahwa Muslim sama sekali tidak mengambil hujjah Abi Balaj, bahkan al-Bukhari menilainya "fibi nadzarun". Penilaian al- 
Bukhari dengan menyatakan "fibi nadzarun" ini mengindikasikan kecaman keras kepada rawi dan termasuk orang yang harus ditinggalkan hadisnya. Dengan demikian, al-Bukhari mustahil menggunakan orang yang dianggap memiliki kecacatan (Abdurrahman, h. 218).

Dalam contoh lain, al-Hakim menyebutkan bahwa terdapat riwayat dengan sanad sebagai berikut:

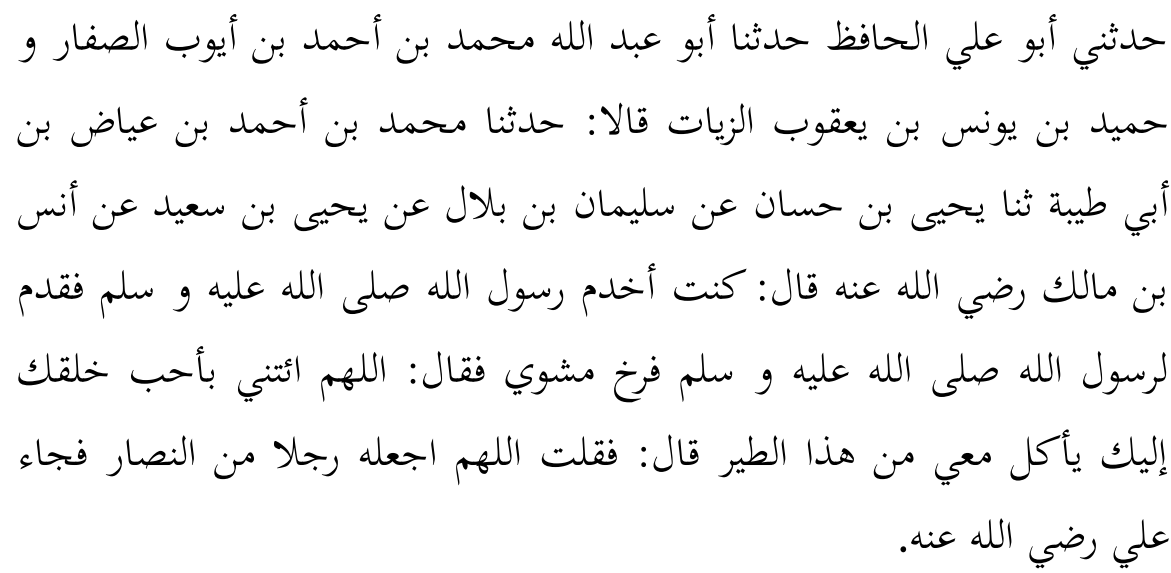

"Telah menceritakan kepadaku Abu 'Ali al-Hafidz, telah menceritakan kepada kami Abu Abdullah Muhammad bin Ahmad bin Ayyub alShaffar dan Humaid bin Yunus bin Ya'qub al-Ziyat, mereka berkta: telah menceritakan kepada kami Muhammad bin Ahmad bin 'Iyadh bin Abi Thaibah, telah menceritakan kepada kami Yahyah bin Hisan, dari Sulaiman bin Bilal, dari Yahya bin Sa'id, dari Anas bin Malik berkata: Aku merupakan pelayan Rasulullah Saw, dan menyuguhkan daging burung panggang kepadanya. Lantas Rasulluah berdoa: "Ya Allah datangkanlah kepadaku seseorang yang Engkau cintai untuk makan bersamaku daging burung ini'”. Kemudian Allah mendatangkan seorang laki-laki dari kaum Nashrani, yakni Ali bin Abi Thalib sebagai jawaban dari doa Nabi".

Hadis ini secara implisit menjelaskan, bahwa Rasulullah Saw pernah memakan daging burung panggang dan berdoa kepada Allah agar didatangkan orang yang paling dicintai-Nya untuk makan bersama. Kemudian doa Rasulullah dikabulkan oleh Allah dan orang tersebut adalah sahabat Ali bin Abi Thalib. Hadis tersebut menurut al-Hakim termasuk hadis 
basan shabih, dengan menyatakan hadis ini sahih sesuai syarat al-Bukhari Muslim dan telah diriwayatkan dari Anas dan sahabat lainnya;

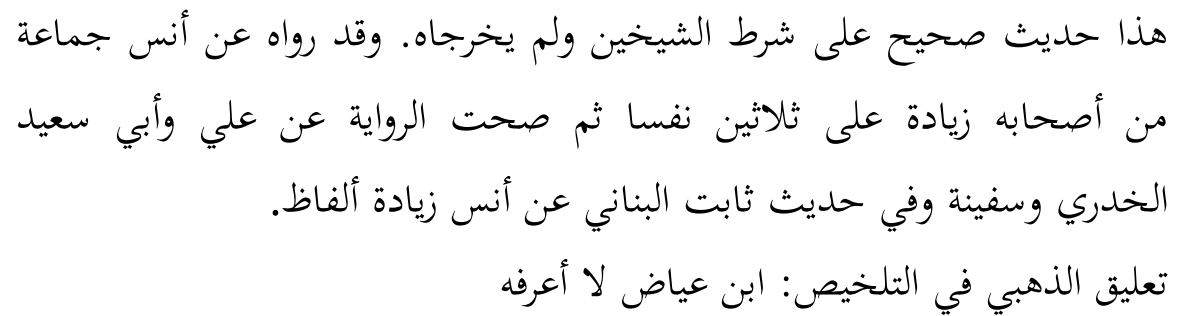

"Ini merupakan hadis sahih dengan syarat al-Bukhari dan Muslim namun mereka tidak meriwayatkannya. Telah diriwayatkan dari Anas dengan sejumlah sahabat lebih dari 30 orang dan diriwayatkan dengan sahih dari Ali, Abu Sa'id al-Khudri, Safinah dan hadis Tsabit al-Banani dari Anas dengan lafadz tambahan".

Dalam keterangan hadis tersebut, al-Dzahabi meragukan hadis ini dalam Talkhis-nya dengan menyatakan bahwa Ibn 'Iyadh tidak dikenal (tidak diketahui). Hal ini merupakan sesuatu yang musykil dari al-Dzahabi. Namun Ibn 'Iyadh yang dimaksud dalam hadis tersebut kemungkinan adalah Ahmad bin 'Tyadh, ayah dari Muhammad bin Ahmad bin 'Iyadh. Dalam biografi Muhammad bin Ahmad bin 'Tyadh yang disebutkan Ibn Hajar, terdapat pernyataan yang mengindikasikan tsiqah kepada Ahmad bin 'Iyadh (al'Asqalani, 2002, h. 193). Selain Ibn Hajar, al-Dzahabi sendiri juga mengatakan hal serupa, bahwa semua perawi hadis tersebut selain Muhammad bin Ahmad bin 'Iyadh adalah tsiqah, sedangkan Muhammad bin Ahmad bin 'Iyadh sendiri termasuk rawi yang shaduq. Di samping itu, al-Dzahabi juga menyebutkan bahwa Muhammad bin Ahmad bin 'Iyad seorang syaikh dari Mesir, alDzahabi tidak menyatakan ia cacat atau tidak dikenal (al-Dzahabi, t.th, h. 465).

Dengan demikian, al-Dzahabi menentang dirinya sendiri dengan menyatakan Ibn 'Iyadh tidak dikenal, dan pada kesempatan lain ia berkata shaduq. Oleh karena itu, hadis riwayat al-Hakim di atas telah diriwayatkan oleh 
para perawi tsiqah dan shaduq (jujur), sehingga hadisnya dinilai hasan dan menjadi shabih dengan banyaknya syahid dari sanad lain.

Kedua, hadis yang sesuai dengan syarat al-Bukhari. Ketika al-Hakim menetapkan adanya hadis yang memenuhi syarat al-Bukhari, ia mengatakan; هadis ini berdasarkan syarat al-Bukhari, tetapi mereka tidak meriwayatkannya). Belum jelas apa yang dimaksud dengan pernyataan tersebut karena al-Hakim tidak menjelaskan secara spesifik dan rinci. Dalam beberapa hadis, al-Hakim seringkali mengalami kekeliruan, sebagaimana ia meriwayatkan hadis;

$$
\begin{aligned}
& \text { حدثنا أبو بكر بن إسحاق حدثنا محمد بن محمد بن حبان الأنصاري حدثنا }
\end{aligned}
$$

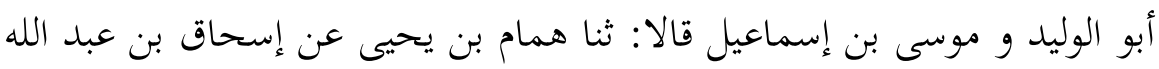

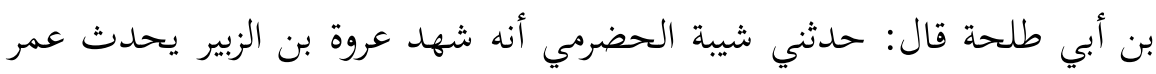

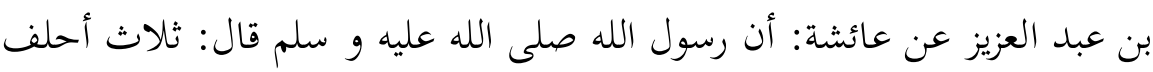

$$
\begin{aligned}
& \text { عليهن: لا يجعل الله من له سهم في الإسلام كمن لا سهم له و سهام الإسلام: }
\end{aligned}
$$

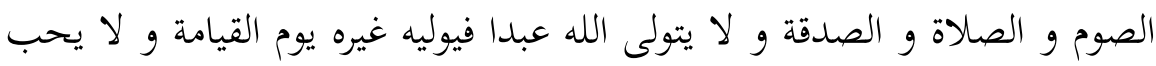

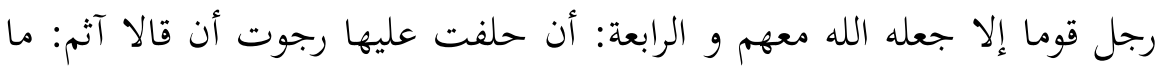

$$
\begin{aligned}
& \text { يستر الله على عبد في الدنيا إلا ستر عليه في الآخرة. فقال عمر بن عبد العزيز: } \\
& \text { إذا سمعتم مثل هذا الحديث يحدث عروة عن عائشة فاحفظوه. }
\end{aligned}
$$

Telah menceritakan kepada kami Abu Bakr bin Ishaq, telah menceritakan kepada kami Muhammad bin Muhammad bin Hibban alAnshari, telah menceritakan kepada kami Abu al-Walid dan Musa bin Ismail, mereka berkata: telah menceritakan kepada kami Hammam bin Yahya, dari Ishaq bin Abdullah bin Abu Thalhah, ia berkata: telah menceritakan kepadaku Syaibah al-Hadhrami yang menyaksikan 'Urwah bin Zubair menceritakan Umar bin Abd al-Aziz dari 'Aisyah, bahwa Rasulullah Saw bersabda: "Ada tiga hal yang saya bersumpah terhadap ketiganya: Allah tidak akan menjadikan seseorang yang mempunyai investasi dalam Islam seperti orang yang tidak memiliki investasi, investasi dalam Islam ada tiga: shalat, puasa, dan zakat. Allah 
Swt tidak akan membela seorang hamba di dunia namun di akhirat Dia justeru menyerahkan kepada selain-Nya untuk membelanya, dan tidaklah seorang mencintai sebuah kaum melainkan Allah Swt menjadikannya bersama mereka, dan yang keempat kalau saya bersumpah atasnya saya berharap tidak berdosa; tidaklah Allah menutup-menutupi aib seseorang hamba di dunia melainkan Allah menutup aibnya pada hari kiamat." Maka Umar bin Abd al-Aziz berkata: "Jika kalian mendengar Hadits seperti ini, seperti hadits Urwah yang ia riwayatkan dari Aisyah dari Nabi Saw, maka hafallah."

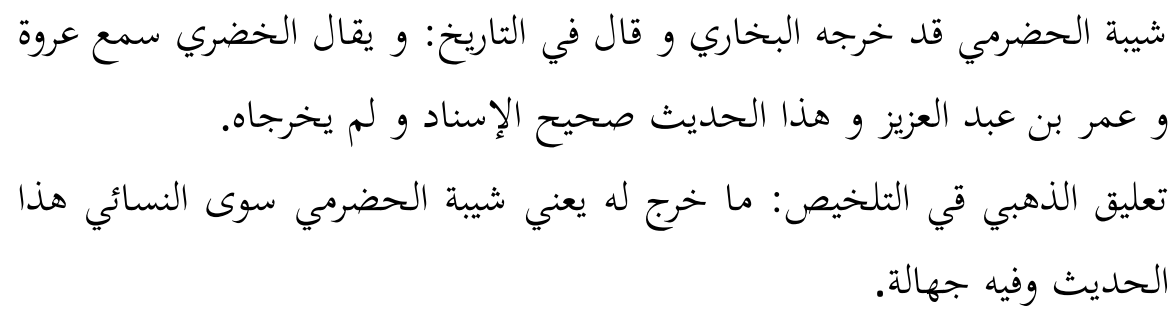

"Syaibah al-Hadhrami telah diriwayatkan al-Bukhari, dan di dalam kitab al-Tarikh disebutkan al-Khadhari yang mendengar Urwah dan Umar bin Abd al-Aziz. Hadis ini shahih sanadnya dan mereka tidak meriwayatkannya". (al-Hakim, h. 19).

Pada hadis ini, terdapat rawi yang bernama Syaibah al-Hadhrami atau Syaibah al-Hadhrami. Menurut al-Hakim rawi ini digunakan al-Bukhari, tetapi menurut al-Dzahabi, al-Bukhari tidak menggunakan Syaibah al-Hadhrami sebagai rawi, karena yang menggunakannya hanya al-Nasa'i. Secara kebetulan hadis tersebut mengandung jabalah (ada rawi yang tidak dikenal), dan alDzahabi menyatakan bahwa Syaibah al-Hadhrami tidak dikenal. Namun dalam pandangan al-Hakim, tidak dikenalnya Syaibah al-Hadhrami tidak menjadi persoalan alot dan krusial, karena hadis majhul tetap boleh dipergunakan, sebagimana yang pernah dilakukan gurunya, Ibn Hibban (Abdurrahman, h. 219-220).

Ketiga, hadis yang sesuai dengan syarat Muslim. Sebagaimana syarat alBukhari, al-Hakim juga memasukkan hadis yang dinilainya memenuhi syarat Muslim dengan mengatakan; هذا حديث على شرط مسلم ولم يخرجاه (Hadis ini sahih 
berdasarkan syarat Muslim, tetapi mereka tidak meriwayatkannya). Berkaitan dengan ini, al-Dzahabi tampaknya tidak pernah sepakat terhadap penilaian alHakim dalam menentukan status rijal al-hadis. Ada distingsi fundamental antara penilaian al-Dzahabi dan al-Hakim, bahwa hadis yang dinilai basan oleh al-Dzahabi dinilai sabih menurut al-Hakim. Hal ini karena konsistensi alHakim dalam memandang kategori hadis shahib juga termasuk kategori hadis basan.

Pernyataan al-Hakim yang menyebutkan suatu hadis telah memenuhi syarat al-Bukhari dan Muslim sebagaimana di atas, dianggap tasabul jika tidak sesuai dengan realitasnya. Hal ini telah dinyatakan Abu Ghadah bahwa alHakim memang merupakan orang yang tasabul. Meski demikian, karya alHakim yang mengkodifikasikan hadis hasan ke dalam hadis shabih bukanlah alasan utama untuk mendakwa ke-tasabul-annya, karena antara shahih dan basan tidak dapat dipisahkan dalam pengaplikasiannya. Namun titik sentral alasannya, di samping beberapa kekeliruan dalam menentukan syarat Syaikhain, al-Hakim juga memiliki kelemahan dalam memahami hadis-hadis yang berkaitan dengan akidah, ibadah, dan hukum halal-haram (Abdurrahman, h. 220).

Keempat, hadis yang sesuai dengan syarat al-Hakim. Selain beberapa istilah yang digunakan di atas, al-Hakim juga menentukan hadis-hadis dalam al-Mustadrak dengan menyatakan; هذا حديث صحيح الإسناد ولم يخرجاه (Hadis ini sahih sanadnya dan al-Bukhari atau Muslim tidak meriwayatkannya). Secara spesifik, al-Hakim sendiri tidak memberikan penjelasan terkait istilah "sahih sanadnya". Namun para ulama hadis setelahnya berusaha menafsirkan sesuai dengan pemahaman masing-masing terhadap penelitian karya-karyanya (Abdurrahman, h. 221-222).

Kategori ini mengindikasikan bahwa hadis yang tercantum dalam alMustadrak, menurut al-Hakim berbeda tingkat kesahihannya. Ada hadis yang 
di-sahih-kan menurut persyaratan Syaikhain, baik secara kolektif maupun secara per-individual; dan ada pula hadis yang di-sahih-kan menurut persyaratannya sendiri terlepas dari persyaratan Syaikhain. Klasifikasi hadis tersebut sejatinya berdasarkan murni dari nalar ijtihadnya untuk menentukan kesahihan hadis. Oleh karena itu, jika pernyataan-pernyataan ini ditolak oleh ulama setelahnya, maka hal tersebut hanya merupakan masalah kbilafiyah dalam mengemukakan metode ilmiah yang disusunnya.

Kelima, hadis yang tidak dinilai al-Hakim. Menurut al-Shan'ani dalam kitab Taudhih al-Afkar, bagian hadis yang tidak dinilai al-Hakim ini disebabkan belum sempat memeriksanya kembali, karena al-Hakim terlebih dahulu wafat dan secara spontan menghentikan proses revaluasi yang akan digagasnya. Bagian ini ada hadis yang sahih dan ada juga yang tidak sahih. Hadis-hadis yang tidak dinilai oleh al-Hakim terbilang dominan pada jilid keempat dalam al-Mustadrak, karena ada sekitar 280 hadis (al-Shan'ani, 2011, h. 75).

Dari sini tampak bahwa tidak semua hadis yang tercantum dalam alMustadrak dinilai al-Hakim, karena masih banyak hadis-hadis yang tidak direvaluasi secara detail. Dengan kata lain, al-Hakim sendiri mengakui bahwa hadis-hadis yang dihimpunnya tidak seluruhnya mempunyai status yang sama. Jika ada hadis yang tidak direvaluasi al-Hakim, dan hasilnya ternyata memenuhi kriteria kesahihan hadis dan ada juga yang tidak memenuhi kriteria, maka al-Hakim menganjurkan agar al-Mustadrak ditelaah kembali agar menjadi relevan untuk diajukan.

Dari kondisi al-Mustadrak sebagaimana di atas, maka dapat dikatakan bahwa hadis yang tercantum pada bagian ini secara ringkas meliputi hadis yang tergolong dhaif dan maudhu'. Sebenarnya hadis yang bermartabat maudhu' pun masih diperselisihkan, seperti yang telah dievaluasi para ulama. Namun demikian, dengan berdasarkan istilah maudhu' atau kadz̧ab, maka secara 
eksplisit hadis yang tergolong maudhu' sangat banyak, bahkan tidak mudah untuk diperhitungkan.

\section{Evaluasi Ulama Terhadap Al-Hakim}

Dalam sepak-terjang penulisan sebuah karya, al-Hakim tidak lepas dari penilaian yang bernada positif ataupun negatif yang dilontarkan oleh para kritikus hadis. Tentang evaluasi positif, banyak pujian ditujukan kepada alHakim yang tampak dari gelar yang dinisbahkan kepadanya. Ini disampaikan oleh para muridnya dan beberapa ahli hadis semasa dan sesudahnya, yakni dengan menyebut al-Hakim sebagai al-hafidz al-kabir, al-naqid, al-syaikh almubadditsin, dan lain sebagainya. Salah seorang yang secara tegas memuji alHakim ialah 'Abdullah Isma'il bin Muhammad al-Anshari dengan menyatakan bahwa al-Hakim termasuk rawi yang tsiqah, faqih, hafids, dan ahli buijah.

Sementara evaluasi negatif juga dilontarkan beberapa kritikus hadis kepada al-Hakim, di antaranya; al-Baihaqi yang merupakan murid al-Hakim, tidak sepakat bahwa al-Mustadrak merangkum hadis yang memenuhi syarat shabihain (al-Bukhari dan Muslim). Kemudian Abu Sa’id al-Malini menilai bahwa dalam al-Mustadrak tidak terdapat hadis sahih yang memenuhi syarat shabihain. Sebagaimana pernyataannya: "Aku telah meneliti al-Mustadrak dari awal sampai akhir, dan ternyata tidak ada satupun hadis yang memenuhi persyaratan shabihain". Sementara al-Dzahabi, meski juga mengkritik alHakim, tetapi menganggap hujatan al-Malini di atas terlalu berlebihan. Berdasarkan penelitiannya, kurang lebih separuhnya yang memenuhi persyaratan shahihain, atau al-Bukhari dan Muslim semata. Sedangkan Muhammad bin Thahir menilai al-Hakim sebagai rafidi khabits (Pengikut Syi'ah Rafidah yang jahat) dan pura-pura Sunni, karena secara realitas ia fanatik sebagai pengikut 'Ali dan tidak menyukai Mu'awiyah (Zainal Arifin, h. 195).

Secara global, para ulama hadis semasa dan pasca al-Hakim banyak mengkritik kelonggaran al-Hakim dalam menilai kesahihan suatu hadis. Ini 
berdasarkan penelitian al-Dzahabi yang seringkali melihat al-Hakim melakukan kekeliruan, semisal dinyatakan sesuai syarat shabihain, namun setelah diteliti sesuai syarat al-Bukhari semata. Tetapi terlepas dari hal tersebut, ijtihad al-Hakim berhasil membawa pengaruh dan kontribusi besar bagi ulama sesudahnya hingga saat ini. Paradigma berpikirnya tampak fleksibel, luwes dan kontekstual dengan situasi pada masanya, dan secara konseptual ia mengaplikasikan aspek ontologi, epistemologi, dan aksiologi dalam menentukan kesahihan hadis.

Selain itu, sebagai tokoh ahli hadis dengan cara berpikir subversif, alHakim mengawali ijtihadnya dengan menguasai dan mengkolaborasikan metode ulama hadis sebelumnya dengan hasil kerangka berpikirnya. Tidak heran jika al-Hakim dinilai sebagai orang yang tasabul, karena ia menelaah hadis dengan metode yang belum dilakukan ulama pada umumnya, yakni pemahaman dengan cara tekstual dan kontekstual, meskipun cara ini tidak jauh berbeda dengan gurunya dan ulama lain pada abad keempat hijriah.

\section{PENUTUP}

Dari penjelasan yang relatif singkat di atas, penelitian ini menghasilkan temuan sebagai berikut: pertama, al-Hakim murni menggunakan prinsip ijtihad dalam menentukan metode kesahihan hadis. Ia membagi konsep ijtihadnya ke dalam empat sudut pandang: (1) Dilihat dari kriteria kesahihan hadis, mencakup syarat rawi harus tsiqah, mengimitasi ulama sebelumnya dengan menggunakan istilah bimitsliba, hadis yang memenuhi kriteria ahli fiqih, dan menerima konsep ziyadah al-tsiqah. (2) Dilihat dari klasifikasi hadis, al-Hakim membagi hadis menjadi dua bagian; shahih dan dha'if (tidak termasuk hadis hasan). (3) Dilihat dari pendekatan status sanad dan matan, al-Hakim memandang prinsip status sanad ada beberapa bagian: ashah al-asanid, asbah alasanid, dan awha' al-asanid, sedangkan pada prinsip status matan, al-Hakim tidak hanya berpegang teguh pada sanad tetapi juga kepada matan. (4) Dilihat dari standar penentuan kesahihan hadis, al-Hakim menerapkan double standart 
yakni tasyaddud (ketat) terhadap hadis-hadis yang terkait dengan akidah dan syari'ah (hukum halal-haram, muamalah, dan nikah) dan tasabul (longgar) terhadap hadis-hadis yang terkait dengan fadhail al-a'mal, sejarah Rasulullah dan para sahabat.

Kedua, kitab al-Mustadrak menunjukkan konsistensi metode al-Hakim dalam menentukan kesahihan hadis. Formulasi langkah yang dilakukan alHakim dalam menentukan kesahihan hadis adalah klasifikasi hadis berdasarkan syarat rawi dengan lima kategori, yakni; (1) hadis yang sesuai dengan syarat shabihain, (2) hadis yang sesuai dengan syarat al-Bukhari, (3) hadis yang sesuai dengan syarat Muslim, (4) hadis yang sesuai dengan syarat al-Hakim, dan (5) hadis yang tidak dinilai al-Hakim. Adapun evaluasi para ulama secara global lebih banyak mengkritik kelonggaran (tasabul) al-Hakim dalam menilai kesahihan suatu hadis, dan juga al-Hakim dianggap sering melakukan kekeliruan. Namun terlepas dari hal itu, hasil pemikiran ijtihad alHakim ini berhasil membawa pengaruh dan kontribusi besar bagi ulama sesudahnya, sehingga jerih-payahnya perlu apresiasi dan komplimen agar tetap memancarkan eksistensinya.

\section{DAFTAR REFERENSI}

Abdurrahman, M. (2000). Pergesaran Pemikiran Hadis; Ijtihad al-Hakim dalam Menentukan Status Hadis. Jakarta: Paramadina

Al-Asqalani, Ahmad bin 'Ali Ibn Hajar. (2002). Lizan al-Mizan, Juz V. Beirut: Maktab al-Mathbu’at al-Islamiyah

Al-Dzahabi, Abu 'Abdullah Muhammad bin Ahmad bin 'Usman. (t.th). Mizan al-I'tidal fi Naqd al-Rijal. Juz III. Beirut: Dar al-Ma'rifah

Al-Dimasyqi, Thahir bin Shalih al-Jaza'iri. (416 H). Tanjih al-Nadzar ila Usbul al-Atsar. Beirut: Dar al-Ma'rifah

Al-Falah, Abu. (t.th). Syarah al-Dhahab fi Akbbari Man Dhabab. Juz II. Beirut: Dar al-Fikr 
Al-Jurjani, Abu Ahmad 'Abdullah bin Addi. (1998). Al-Kamil fi Dhu'afa alRijal. Juz I. Beirut: Dar al-Fikr

Al-Naisaburi, Abu 'Abdullah al-Hakim. (1978). Al-Mustadrak 'ala al-Sabihain. Juz I. Beirut: Dar al-Fikr

Al-Shan'ani, Muhammad bin Ismail al-Amir. (2011). Taudhih al-Afkar. Jilid II. Riyadh: Maktabah al-Rasyad

Al-Shiddiqy, T. M. Hasbi. (1988). Sejarah dan Pengantar Ilmu Hadis. Jakarta: Bulan Bintang

Al-Thahan, Mahmud. (1995). Metode Takbrij Penelitian Sanad Hadis. Surabaya: PT. Bina Ilmu

Amarudin dan Mufid, Syafril. (2013). Metode Keshahihan Hadis Al-Hakim (Telaah Atas Kitab al-Mustadrak 'ala al Shahihain. Jurnal Syabadab, 1 (2).

Arifin, Zainul. (2010). Studi Kitab Hadis. Surabaya: al-Muna

Fauzan, Agusri. (2018). Studi Komparatif Teori Ilmu Hadis Al-Hakim AlNaisabury Dan Ibnu Shalah. El-Afkar, 7 (1)

Isma'il, Syuhudi. (1998). Kaedah Kesahihan Hadis. Jakarta: Bulan Bintang

Katsir, Abu al-Fida' Ibn. (1977). Al-Bidayah wa al-Nibayah. Juz II. Beirut: Dar al-Fikr

Najwah, Nurun. (2003). "Al-Mustadrak 'ala al-Shahihain al-Hakim" dalam Studi Kitab Hadis. Yogyakarta: Teras

Wahyudi, Arif. (2013). Mengurai Peta Kitab-kitab Hadis (Kajian Referensi Atas Kitab-kitab Hadis). Jurnal al-Ahkam, 8 (1) 